\title{
Explaining the Success of the Asian NICs: incentives and technology
}

\author{
Martin Fransman
}

\section{Introduction}

This article examines the role of incentives and technological change in the economic performance of the Asian newly industrialised countries (NICs). To begin, it sets out a number of hypotheses which have been advanced in various parts of the literature to explain their successful economic record. The hypotheses may be grouped into two categories according to whether international or national factors are dominant.

\section{International factors}

i) The 'state of the world economy', which explains the simultaneous rise from the mid-1960s of the Asian and Latin American NICs, most of which have had very different histories and natural endowments. (Important variables include the growth of world trade, availability of international credit and direct foreign investment.)

ii) The international diffusion of technology and the 'catch-up process'.

iii) Geopolitical factors (for example, the strategic interest, particularly of the US, in count ries like South Korea and Taiwan in the post-war period, and the importance of Japanese colonialism in the same countries).

\section{National factors}

iv) The establishment by the state of correct prices and incentives, which have facilitated an efficient private allocation of resources in accordance with the country's short-run comparative advantage.

v) Direct allocation of resources by the state, rather than through market processes, in order to develop areas of the economy perceived by the state to have longer run potential.

vi) Natural endowments and the country's historical and cultural inheritance (eg ports in the case of Hong Kong and Singapore, efficient agriculture resulting from land reform in Taiwan and South Korea, the inheritance of a relatively rich stock of skills and attitudes to work, etc).

vii) Specificities of the labour market emphasising, depending on the writer's views, the positive effects of the absence of strong trade unions on the efficient functioning of the labour market, or the subordination of labour in order to serve the sectional interests of capital.

While all these hypotheses have appeared in the literature, and while all those who have written on the Asian NICs have stressed the importance of more than one of them, it is hypotheses iv) and, to a lesser extent, v) that have tended to dominate the discussion. For this reason the arguments of two authors who have perhaps been most influential in supporting hypothesis iv), Little and Balassa, will be briefly examined in the next section.

\section{The Views of Little and Balassa}

For Little (whose views are expressed in a number of places including Little [1979] and various parts of Little [1982]) the economic success of the Asian NICs 'can be attributed to good policies and the people'. Although international factors such as the ability to borrow and the attraction of foreign investment have been important in varying degrees for the Asian NICs, these factors themselves are 'primarily a matter of domestic policies' [Little 1979:36].

But what are the 'good domestic policies' to which Little refers? The central point is that national policy must facilitate an allocation of resources in accordance with the country's short run comparative advantage. Accordingly, investment criteria must be consistent with comparative advantage: investment planning criteria and the analysis of comparative advantage, originally two separate specialisations in economics, have come together. This is as it should be, since, in an open economy, they must be the same thing' [Little 1982:138]. Furthermore, every economy is open in the sense that the possibility of international

WDS Bulletin. 1984. vol 15 no 2. Institute of Development Studies. Sussex 
trade exists. When investment is consistent with comparative advantage, and accordingly when national policy does not discriminate against exports, the latter will grow. Little therefore concludes that 'export incentives (and disincentives) do work... That incentives work is shorthand for saying that export demand and domestic supply are both elastic. Export pessimism had been based largely on gloomy views about the growth and elasticity of world demand' [Little 1982:139]. In the case of the Asian NICs, Little stresses the positive effects of the introduction of 'almost free trade conditions for exports':

The major lesson [emerging from the study of South Korea, Taiwan, Hong Kong and Singapore] is that labour-intensive export-oriented policies, which amounted to almost free trade conditions for exporters, were the prime cause of an extremely rapid and labour-intensive industrialisation which revolutionised in a decade the lives of more than 50 million people, including the poorest among them [Little 1979:34, 1982:141,262].

The next step in the casual chain links the growth in exports with growth in output and employment:

While the export boom can certainly be attributed to the policy reforms resulting in such trade regimes, it would be wrong to attribute the whole success of these countries, in terms of employment, growth, and income distribution, to such trade policies. Nevertheless it is impossible to doubt that they played a very large role [Little 1982:141].

There is strong evidence that output and growth improve as a higher proportion of domestic production is exported. Among the reasons given for this by Bhagwati were that consequentially increased imports reduced the chaos in the pattern of import substitution incentives and ensured a freer flow of inputs with benefits for capacity utilisation and the size of stocks held. The growth of exports made it easier to borrow, and more direct foreign investment was attracted, some of it to the relatively labour-intensive export sector. It seems to me that another more dynamic reason, valid at least for the Far Eastern countries, was that exports were very profitable at both actual and shadow prices and that this led to a rise in savings and investment [Little 1982:142].

In passing it should be noted that Little acknowledges that, with the exception of Hong Kong, the Asian NICs have adopted near-free-trade only in the export sector: 'Hong Kong has always been as pure laisser faire as conceivable; the others are far from laisser faire but adopted virtually free-trade policies for exporters in the early or mid-1960s' [Little 1982:262].

We are now in a position to summarise Little's neoclassical 'story of capital accumulation and the adjustment to changing factor prices':

Consider the following propositions. As investment proceeds, [and we may add, as exports expand] the demand for labour rises. Eventually, provided it proceeds fast enough to more than cope with a growing population, this will cause a rise in real wages and a fall in the rate of profit, which in turn will cause the introduction of more capitalintensive techniques. These propositions are the essence of a neoclassical theory of growth. They look like a very reasonable description of the history of the developed countries, and more recently of South Korea, Taiwan, Hong Kong, Singapore, and possibly others. They seem to presuppose only profit maximisation, and not necessarily perfect competition. It does not require any statement to the effect that the rate of interest is equal to the marginal productivity of capital, for the amount of capital and changes in it can be left undefined' [1982:23-4].

With regard to technology Little argues that there is a significant degree of substitutability between the labour and capital in puts with the result that 'there is a lot of room for selecting more labour-intensive techniques of production while taking the shelf of known and available techniques as given' [1982:180]. Accordingly:

Recent stress on the inappropriateness of existing technology has been overdone. The earlier vision, that one of the great advantages of backwardness is that more modern techniques can be acquired from abroad far more cheaply than they can be developed and invented, is still valid... Korea, Taiwan and Hong Kong have shown that a sufficiently labour-intensive development ... was possible without any need to develop new labourintensive methods [1982:181].

Little's perspective on the Asian NICs follows directly, as he informs his readers in the second chapter of his 1982 book, from his starting paradigm:

Neoclassical economics can thus be described as a paradigm that tells one to investigate markets and prices, perhaps expecting them often to work well, but also to be on the watch for aberrations and ways of correcting them. Perhaps the single best touchstone is a concern for prices and their role. It is not a central tenet of a neoclassical outlook that the price mechanism will achieve Pareto-optimality in production [Little 1982:25-6].

The views of Balassa as expressed in his edited volume [1982] are similar to those of Little. This large study involves an examination of trade incentives and economic performance in the late $1960 \mathrm{~s}$ in 11 semiindustrial countries, which in 1973 produced 68 per cent of the exports of manufactured goods by the 
developing countries. A further 16 per cent came from Hong Kong. These countries were distinguished according to the outward - or inward - orientation of their development st rategies where this was defined according to 'the absence, or presence, of an antiexport bias'. They were divided into four groups, the first of which, consisting of South Korea, Singapore and Taiwan, is of interest for present purposes. The latter countries 'avoided a bias against exports and against primary activity, provided broadly equal incentives to most exports ... ensured the stability of the incentive system, [and] had the best export performance' [59]. As with Little, while increased exports result from the incentive system which does not discriminate against exports, the consequences is an increase in economic growth:

Export expansion appears to have had beneficial effects on economic growth... These results reflect the benefits derived under an outward-oriented strategy from resource allocation according to comparative advantage, increased capacity utilisation, and the exploitation of economics of scale. Gains in employment may also be obtained as exports increase the demand for labour and thereby improve income distribution. The rise in real wages and lessened discrimination against agriculture also tend to reduce income inequalities. The expansion of exports and the consequent growth of GNP have been the result of the incentives applied [59].

Furthermore, Balassa argues, export expansion may contribute to growth 'by easing the foreign exchange bottleneck that has often been an obstacle to economic growth in developing countries'. In addition, apart from these once-for-all gains, 'such policies may provide a continuing stimulus to economic growth through technological change that is undertaken in response to competition abroad, increased savings, and the more efficient use of increments in factor supplies' [51].

\section{Some Complications}

The chain of causation in the explanation of the economic performance of the Asian NICs offered by Little and Balassa can be represented roughly as follows: short run comparative advantage $\rightarrow$ investment $\rightarrow$ exports $\rightarrow$ economic growth $\rightarrow$ (eventually) rising real wages $\rightarrow$ falling rate of profit $\rightarrow$ choice of more capital-intensive techniques. (Little is more explicit than Balassa about the latter part of the casual sequence.)

However, there are a number of complications with this explanation, some of which will be discussed briefly here.

\section{Economic theory and the Asian NICs}

While, as shown above, both Balassa and Little point to an empirical association between exports and economic growth in the Asian NICs, and provide some loosely formulated reasons for this association, the theoretical casual mechanism linking exports and economic growth is less clear. Some aspects of this observation were elaborated in an important conference on the advanced developing countries in the Pacific Basin, the proceedings of which were published in 1981 [Hong and Krause 1981].

In one of the papers, Krueger, who undertook one of the major studies on the export-promoting countries [Krueger 1978], discusses the relationship between free trade, exports and economic growth. 'At first glance', she notes, 'the superiority of the exportpromotion strategy appeared to vindicate the view of trade theorists, who had advocated free trade and who saw export promotion as coming closer to a free trade' regime than did import substitution [Krueger 1981:3] However:

The simple $2 \times 2$ comparative advantage model would seem to suggest that growth rates will be the same under autarky and under free trade, once the once-and-for-all losses associated with accepting a non-optimal trade policy are absorbed. Thus, there are no theorems from standard trade theory with regard to the effect on the growth rate of departures from optimal trade policy [6].

Secondly, Krueger points out, 'the difference in growth rates [between the "outward" and "inward" oriented economies] seems to be greater than can conceivably be accounted for by the exporting sector of the economy'. [4]. (For evidence that domestic demand expansion has been much more significant than export expansion as a source of growth of manufacturing demand in South Korea, and even more so in Japan, see Nishimizu and Robinson [1983:25]). Krueger therefore concludes that 'What emerges is a set of questions which call for a great deal of research. It is not enough to know that export promotion outperforms import substitution. It is equally important to understand why' [Krueger 1981:5]. In her paper Krueger goes on to examine dynamic effects in infant industries under exportoriented regimes.

\section{The empirical study of the South Korean case}

Further complications are raised by the careful empirical study of South Korea. In the same conference collection Chong Hyun Nam [1981] provides a comparable updating for 1978 of Westphal and Kim's estimates of effective rates of protection and effective subsidies for the year 1968. To the extent that these magnitudes provide an adequate indication 
of prevailing incentives, ${ }^{1}$ Chong Hyun Nam's figures raise a number of difficulties.

In the first place, far from South Korea 'avoiding a bias against exports and against primary activities' [Balassa 1982:59] Chong Hyun Nam shows that 'the relative incentives accorded to the manufacturing sector, which accounted for nearly 90 per cent of exports in 1978, reveal that export sales, on average, receive greater incentives than domestic sales, with 16 per cent effective incentives for export sales versus four per cent protection for domestic sales' [Chong Hyun Nam 1981:205]. In commenting on the 16 per cent figure, Corden states that 'this figure seems surprisingly low ... It would not be surprising if an alternative calculation yielded a figure pf perhaps 30 per cent' [Hong and Krause 1981:212]. The effective subsidies for exports are largely the result of the ready availability of credit at substantially below market rates of interest [Chong Hyun Nam 1981:195]. In the case of primary activities Corden concludes that 'protection for agriculture is very high, averaging more than 70 per cent, and has greatly increased since 1968. This alone is sufficient reason not to describe Korea as a "free trade" country" [Hong and Krause 1981:212].

Accordingly, far from avoiding a bias against exports and primary activities, South Korea has discriminated in favour of these activities. This presents further problems for theory, as Findlay points out:

In terms of the standard theory of trade and welfare, a bias in favour of exports is no better in principle than a bias against them ... In comparison with the optimal free trade level a "right wing deviation" in trade policy that discriminates in favour of exports is no better than the equivalent "left wing deviation" that discriminates in favour of import substitution. It is therefore hard to see why an export-promotion strategy should produce such successful results, since both types of bias are equally to be condemned from the standpoint of static allocative efficiency [Hong and Krause 1981:31].

Findlay concludes that "it is clear that an answer must be sought outside the conventional bounds of the standard model, in the murky but relevant waters of

\footnotetext{
Krueger notes that 'it is impossible for any researcher to estimate the value, which must have been considerable, of the informal incentives which the government provided to exporters ... This included the attention of the highest officials to exporters' difficulties; the somewhat more lenient perusal of tax returns than happened to other businesses; the more rapid expedition of paperwork and government formalities... No one has yet devised a means of estimating the importance of these types of considerations, but it cannot be doubted that they affected the relative profitability of exporting contrasted with production for the domestic market' [Hong and Krause 1981:215]. See also Jones and SaKong [1980].
}

such concepts as X-efficiency and "learning by doing"' [31].

However, the South Korean economy has not only been trade-biased (ie discriminated in favour of exports), it has also been industry-biased (ie discriminated in favour of certain productive sectors of the economy). As was shown earlier, Little and Balassa have stressed the importance of the introduction of near-free trade, and therefore the following of short run comparative advantage, in the export sector. However, parts of the South Korean economy have been heavily protected although, as we shall see, exports have also been important from these protected sectors. Chong Hyun Nam notes that 'despite the import liberalisation attempts since the early 1960s, most of the import-substitution industries are still highly protected by various import controls' [187]. In effect "there seems to have been little if any overall import liberalisation during the 1968-78 period' [202]. While the effective rate of protection in 1978 for the manufacturing sector was relatively low at 5.3 per cent (Balassa method), this aggregate figure conceals a wide variation. Furthermore, the high rates of effective protection were not confined to the socalled heavy industrial sectors (the development of which has been criticised as a result of its capital-and foreign-exchange intensity by Little [1982:11,146,241; 1979:32] and Lal [1983:45-8]). The effective rate of protection in 1978 for the five most heavily protected sectors of the economy was as follows: transport equipment, 135 per cent (mainly ships - South Korea has now become a major world exporter of ships); consumer durables, 131 per cent; agriculture, forestry and fishing, 77 per cent; machinery, 47 per cent; and non-durable consumer goods, 32 per cent. While, as we have seen, authors like Little have praised South Korea for its 'good policies' in the export sector, surprisingly little is known about the significance of the more highly protected sectors for economic performance. As Corden notes:

With regard to protection of manufactures for the home market one needs to know how significant the high protection cases are, how important are they at a point in time in terms of value added and employment, and what role have they played in the growth process. Furthermore, it would be interesting for example to have an explanation for the reasons for the particular pattern of dispersion [of effective rates of protection] with regard to the roles, of sectional pressures, of assessment of future world market prospects, and of particular philosophies of development [Hong and Krause 1981:213].

The writer who has perhaps been most aware of the departure of the South Korean case from the standard 
trade and industry models is Westphal. In an important article [1981a] Westphal criticises the view that "the closer is the policy regime to free trade, the better is the industrial performance, because a free trade regime necessarily means uniformity of incentives $v i s-\dot{a}$-vis trading opportunities and empirically appears to assure the requisite high levels of export achievement' [1]. In his study of infant industry protection in South Korea Westphal argues that the industry-bias and relatively high rates of protection in selected industries is a source of strength rather than weakness, since it is precisely the discrimination that encourages the growth of these infant industries. Furthermore, he cites evidence to suggest that in some cases, though not necessarily all, inf ant industries have rapidly achieved international competitiveness. However, both here and in Westphal [1981b], it is stressed, in line with the above arguments of Krueger and Findlay, that a particular importance attaches to the exporting activities of infant industries as a result of the advantages that such activities provide. With regard to economic theory Westphal also notes that in South Korea " "tailor made" infant industry protection has typically been afforded via quantitative restrictions on imports' [Westphal $1981 \mathrm{~b}: 16$ ]. This flies in the face of standard theory and policy conclusions which suggest that subsidies are to be preferred, followed, in this order, by tariffs and lastly quantitative restrictions on the grounds that the correct use of the former instrument comes closest to correcting distortions of their source [Corden 1974; also Little 1982:68,70,140].

It should by now be clear that we have moved some way from the worldview expressed by Little and Balassa. First of all the link between free trade on the one hand and economic growth on the other is weakened if not broken. Thus a recent article concludes that 'Westphal's argument holds up the hope that the benefits of export expansion on total factor productivity growth can be realised simultaneously with the protection phase, but only if the incentives are tied to export performance' [Nishimizu and Robinson 1983:32, emphasis added]. Secondly, if protected infant industries are to play an important role in the development process, as Krueger, Findlay and Westphal suggest, then the use of short run comparative advantage as a 'guide post' to resource allocation is far more restricted than suggested by Little and Balassa. By definition, infant industries do not enjoy a short run comparative advantage. This raises, thirdly, the question of how governments should go about selecting industries for promotion. Furthermore, it would be helpful, as Corden suggests, to know more about how governments such as those of South Korea and Japan, have in practice selected industries and firms for special promotion. Fourthly, the instruments chosen by the South Korean Government to protect infant industries, namely the preference for quantitative restrictions, suggest that the time may be ripe for a rethink of the standard arguments regarding the costs and benefits of subsidies, tariffs and quantitative restrictions. Similarly in Japan, industries selected for development 'were afforded the protection of high tariffs and quantitative import controls' [Allen 1981:90]. This is implied by Westphal when he notes it is not my purpose to inquire why most governments appear to favour protection as the principal instrument of infant industry promotion or to argue that they are correct in this respect. Instead, I simply want to establish that infant industry protection can "work" in the sense of fostering the rapid achievement of internationally competitive levels of productivity' [Westphal 1981a:16]. While the relative merits of subsidies, tariffs and quantitative restrictions have hitherto been discussed within the conceptual framework of static resource allocation, it would seem to be necessary in any 'rethink' to take account of the crucial question of uncertainty. From the point of view of a government such as that of South Korea, which seems to have been concerned to encourage and, at times, coerce private firms to move into particular areas of production, one of the main advantages of using quantitative restrictions is that they provide the firms concerned with a greater degree of certainty regarding market size and hence sales and profitability than do tariffs (unless prohibitive) or subsidies.

\section{The Technology Dimension}

Let us recall the role played by technological change in the discussion thus far of the explanation of Asian NIC economic performance. (Technological change here may be thought of as new ways of transforming inputs into outputs, including the production of new or altered products.) Technological change has entered the discussion in two areas: first, in connection with the dynamic effects of exports on growth, productivity and the attainment of international competitiveness - Findlay's 'murky waters of Xefficiency and learning-by-doing'; and secondly, via Little's discussion of the choice of increasingly capitalintensive techniques when real wages eventually begin to rise, thus economising on increasingly scarce labour resources. However, if the explanandum is the economic performance of the Asian NICs, including their output and productivity growth, then it is clear that the technology dimension merits further attention.

To begin with, it is interesting to compare Little's account of the propositions of neoclassical growth theory referred to above with Hicks' discussion of 'the mainspring of economic growth' which he discussed in his Nobel Prize address [Hicks 1981]. Notable is the extent of agreement in terms of causation. In 
discussing the characteristics of 'the double-equilibrium path' (ie savings-investment equilibrium and full employment) Hicks notes: 'This is the chain of causation: from investment to final output, from final output to wages, from wages to the rate of profit on new investment, and thence back on investment itself - the latter step in the substitution of capital for labour' [127]. However, for Hicks the role of technological change is central in initiating this casual sequence: 'The mainspring of economic progress ... is invention; invention that works through the rate of profit: Each invention gives an impulse' to the economy [28]. Accordingly an understanding of the innovative process is important: 'it would help us to understand the innovative process, as it works in this century, and so to know, better than we do, how far we can count upon steadiness in the flow of innovation' [29].

Similarly, in understanding the mainspring of economic growth in the Asian NICs the role of innovation is also central. However, in the case of these and other developing countries the innovative impulse comes primarily from outside, through technology imports. These imports are facilitated by the earnings of foreign exchange through exports and in turn they enable further increases in productivity for both the domestic market and exports. Accordingly, exports influence economic growth, not only through direct dynamic effects, but also indirectly through the import of improved processes and products. However, it is now recognised that the successful import of technology is a far more complicated process than was believed.

Although it is relatively simple to import and use a machine, most technology imports are far more complex (eg the import of entire processes and plant). The problem is that even where blueprints and other details are provided by the technology supplier, there is still a large element of what Nelson has referred to as 'implicitness' in the technology being transferred. Furthermore, the technology will have to be adapted to conditions that are always, to a greater or lesser extent, unique in the using firm. Accordingly, a degree of indigenous technological capability is required in a successful transfer of technology. Such capabilities will also be necessary in the initial search and evaluation of technologies (cf hypothesis (ii) above).

To some extent developing countries will benefit from an ability to bring about technological change that is not functionally related to the process of successfully importing technology. While there are other examples, that cited most frequently in the literature is the social desirability of establishing a capital goods sector that will facilitate the adaptation and modification of processes and products which play an important role in the growth process. Economists are now coming to realise that the cumulative significance of such incremental changes is probably greater than that of major technological changes. An important set of questions arises in determining how far a country should go at any point in time in developing local technological capabilities rather than importing technology. However, the economist's usual injunction that the long-run social benefits must exceed the longrun social costs will usually not be of great use in facilitating decisions $e x$ ante as a result of the unpredictable elements influencing such costs and benefits.

Nevertheless, there will eventually come a stage in the country's industrial development when it will be socially and, possibly, privately profitable to enhance substantially local technological capabilities. In the USA and Japan this came relatively late in the industrialisation process. However, Westphal more than anyone else has argued that 'deep' levels of knowledge and technology are not necessary in the earlier stages of industrialisation. He and Dahlman argue that 'as Korean experience demonstrates ... high indigenous levels of all types of technological mastery are not necessary for the initial stages of industrial development; in the Korean case, a mastery which has been mainly confined to production engineering has been sufficient' [Dahlman and Westphal 1982:133]. While the comments in this and the previous paragraph have dealt with technology imports and local technological capabilities, a dimension that has been missing in much of the discussion of the effect of incentives in the Asian NICs, the question referred to above regarding the relationship between exporting and improvements in productivity and output is also central, though no more will be said about it here.

Finally, efficient production, including production for exports, is the result of a complex interplay of a large number of factors of which prices are only one, although they are very important. Anyone even slightly familiar with the Japanese case will realise the importance of non market processes in the sphere of production. Yet, as Leibenstein notes 'mainline theory does not address itself to the non market production activities within the firm . . X-efficiency theory focuses on these considerations' [Leibenstein 1981:105]. Any attempt to explain the economic performance of the Asian NICs cannot afford to exclude a careful analysis of these non market processes.

\section{Conclusion}

If a single conclusion emerges from this article it is that we are still a long way from a comprehensive 
explanation of the economic performance of the Asian NICs. Not surprisingly, this conclusion is reminiscent of that emerging at the end of the long debate in the economics literature on the causes of differing growth rates. Our degree of ignorance may still be relatively great, but as the discussion here of the South Korean case shows, there is a good deal to be learned from the detailed empirical study of this and other Asian NICs.

\section{References}

Allen, G. C., 1981, The Japanese Economy, Weidenfeld and Nicolson, London

Balassa, B. (ed), 1982, Development Strategies in Semi-industrial Economies, Johns Hopkins University Press, Baltimore

Chong Hyun Nam, 1981, 'Trade and industrial policies, and the structure of protection in Korea' in W. Hong and L. B. Krause (eds), 1981

Corden, W. M., 1974, Trade Policy and Economic Welfare, Oxford University Press

Dahlman, C. and L. Westphal, 1982, 'Technological effort in industrial development - an interpretative survey of recent research' in

F. Stewart and J. James (eds), The Economies of New Technology in Developing Countries, Frances Pinter, London

Hicks, J., 1981, 'The mainspring of economic growth', The American Review, vol 71 no 6, pp 23-32

Hong, W. and L. B. Krause (eds), 1981, Trade and Growth of the Advanced Developing Countries in the Pacific Basin. Papers and Proceedings of the Eleventh Pacific Trade and Development Conference, Korea Development Institute, Seoul
Jones, L. P. and 1. SaKong, 1980, Government, Business and Entrepreneurship in Economic Development: the Korea case. Studies in the Modernisation of the Republic of Korea, 1945-75, Harvard University Press, Cambridge (Mass)

Krueger, A. O., 1978, Foreign Trade Regimes and Economic Development: liberalisation attempts and case queries, Ballinger Press, Cambridge (Mass)

-1981, 'Export-led industrial growth reconsidered' in W. Hong and L. B. Krause (eds), 1981

Lal, D., 1983, The Poverty of 'Development Economics', Hobat Paperback 16, The Institute of Economic Affairs, London

Leibenstein, H., 1981, 'Microeconomics and X-efficiency theory: if there is no crisis, there ought to be' in D. Bell and 1. Kristol (eds), The Crisis in Economic Theory, Basic Books, New York

Little, 1. M. D., 1979, 'The experience and causes of rapid labour-intensive development in Korea, Taiwan, Hong Kong and Singapore and the possibilities of emulation', ILO Working Paper WPIl-1, ARTEP, 1LO, Bangkok

-1982, Economic Development - Theory, Policies and International Relations, Basic Books, New York

Nishimizu, M. and S. Robinson, 1983, 'Trade policies and productivity change in semi-industrialised countries', Discussion Paper Report no 52, Development Research Department, World Bank, Washington DC

Westphal, L., 1981a, 'Empirical justification for infant industry protection', Staff Working Paper no 445, World Bank, Washington DC

-et al, $198 \mathrm{lb}$, 'Korea industrial competence: where it came from', Staff Working Paper no 469, World Bank, Washington DC 